\title{
AN IMPROVED MODEL FOR ESTIMATING RUNWAY ACCIDENT COST IN NIGERIA
}

\author{
Akinyemi Olasunkanmi Oriola ${ }^{1}$, Adebiyi Kazeem Adekunle ${ }^{2}$ \\ ${ }^{1}$ Mechanical Engineering Department, Olabisi Onabanjo University, Ago-Iwoye, Nigeria \\ ${ }^{2}$ Mechanical Engineering Department, Ladoke Akintola University of Technology, Ogbomoso, Nigeria
}

Received 6 November 2014; accepted 3 February 2016

\begin{abstract}
This research proposes an improved model for estimating runway accident cost in the aviation industry in Nigeria. Bayesian Network was used to model the probability of consequences of runway accidents and subsequently the cost of the potential consequences. The Bayesian Network was also used to implement causal and diagnostic inference. Market interest rate which incorporates the effect of inflation was included to relax the assumption of constant economic value. The three classes of consequences of runway accidents identified in this study were fatal, serious, and minor. Domain experts were used to obtain relevant Bayesian causes and evidences related to the occurrence of consequence of runway accident. A mathematical equation was developed to solve the Bayesian Network influence diagram to obtain the probability of minor runway accident, serious runway accident and fatal runway accident as $0.7603,0.1547$ and 0.0850 respectively. Consequently, the estimated cost of runway accident (minor, serious and fatal) was \$23, 813.52, \$20, 052.64 and \$772, 856.06 respectively. The Bayesian Network diagnostic inference reveals the close relation of runway accidents in Nigeria aviation sector with aircraft system failure, approach/takeoff procedures, human factors, weather conditions and collision risk.
\end{abstract}

Keywords: consequence, inflation, runway accident, Bayesian.

\section{Introduction}

The need for the implementation of effective runway safety programmes requires the need to quantify the cost of consequences of runway accident. This research work considered two types of runway accidents namely runway incursions and runway excursions (Akinyemi and Adebiyi, 2015). A runway incursion is any unauthorized intrusion onto a runway, regardless of whether or not an aircraft presents a potential conflict (FAA, 2008a; FAA, 2012). The worst aircraft accident in aviation history happened in 1977 and it was a runway incursion involving two Boeing 747 aircraft in Tenerife, the Canary Islands resulting in the loss of 583 persons (Aviation Safety Network, 2008). On the other hand, runway excursions include events of two types: veer-offs, in which an aircraft goes off the side of a runway, and overruns, in which an aircraft runs off the end of a runway (FAA, 2008b). Runway excursion comprises $96 \%$ of all runway accidents; $80 \%$ of fatal runway accidents and $75 \%$ of related fatalities (Werfelman, 2008). Although these accidents have been the subject of a few studies, the number has been relatively small and the recommended

${ }^{1}$ Corresponding author: aooakinyemi@oouagoiwoye.edu.ng 
preventive measures have been relatively few compared with numerous programmes devoted to runway incursions (Kirkland et al., 2004; Werfelman, 2008).

For years, any discussion of runway safety has emphasized runway incursions. Many of the researches and groups involved with the Runway Safety Initiative (RSI) already have developed products intended to prevent runway incursions, only a few existing products address runway excursions. Prominent among published works in this area include those of Yong and Wang (2001), Luxhoj (2003), Scarborough et al. (2003), James et al. (2006), Luxhoj et al. (2006), Rankin (2006), Stroeve et al. (2006), Ting (2007), Wischmeyer (2007), Christoph et al. (2008), Scarborough et al. (2008) and Williams (2008). These works have extensively discussed runway safety, the human factors contribution to runway incursion, risk assessment and performance evaluation of capacity enhancing technologies. Data have also shown that efforts are being effective in preventing runway incursion, but the number of incidents and their severity still indicates a very high risk.

The threat of air traffic/runway accidents on our airways/runways has called for sober reflection at the local, national, and international levels. This is due to the resulting losses, of both human and material resources (Adebiyi, 2008). The consequences of air traffic/runway accidents are described in terms of number of injuries and the level of damage to the aircraft. Injuries are classified into three groups: minor, serious and fatal. Similarly, damage to aircraft is also described according to three classification group: minor, substantial damage and aircraft destroyed. Adebiyi (2008) had postulated that putting a cost on air travel accidents will draw the attention of the employees, society, and the management on the need for organized safety programmes. Most researches that have been carried out on aviation safety have concentrated on risk reduction and accident prevention with emphasis on design, maintenance and operation of aircraft (Luxhoj, 2003; Luxhoj et al., 2006). Harold and Moriarity (1990) stated that since accident occurrence is probabilistic in nature, its cost estimation model should also be the same. This eventually formed the basis of the air traffic accident cost estimation model developed by Adebiyi (2008). However, the expression of the probability of air traffic accident used in this model does not present the true probability of consequence magnitude given the occurrence of causes of accidents. Rasmussen (1981) stated that the calculation of consequence magnitude of accidents will of course depend upon the type of hazard. Hence Bayesian Network (BN) was used to model this shortcoming. Luxhoj (2003) and Luxhoj et al. (2006) used Bayesian Network to develop a risk based decision support tool to evaluate the effectiveness of technology intervention against runway incursion. In addition, Li et al. (2012) used a fuzzy Bayesian network methodology to improve the quantification of organizational influences in Human Reliability Analysis (HRA) frameworks; Jones et al. (2010) used Bayesian network methodology for maintenance planning in a manufacturing industry.

In this study, a Bayesian probabilistic expression was developed to improve/modify the air traffic accident cost estimation model earlier developed by Adebiyi (2008). In addition, market interest rate which incorporates the effect of inflation was 
incorporated to relax the assumption of constant economic value. This modification for each class of runway accidents (minor, serious and fatal) is necessary to justify the need for safety intervention and for evaluating the financial implication of runway accidents on the national economy.

\section{Construction of Bayesian Network (BN) Model}

In this study, runway hazards leading to runway accidents have been categorised into six groups. It should be noted that these hazards are mutually exclusive and independent of one another. Each occurrence will have its respective consequence magnitude. Bayesian Network was used to determine the probability of consequence magnitude of runway accident given the occurrence of runway hazards. Fig. 1 depicts the Bayesian influence diagram for the relationship between runway hazards (parent nodes) and consequence magnitude of runway accident (child node). For each node, the conditional probability of that node taking a certain value given the values of its parents is needed. This amounted to defining/generating a conditional probability table (CPT) for the child nodes (consequence magnitude) in Fig. 1. It should be noted that in a CPT, the probability expression is replaced by probability values between 0 and 1 consistent with the standard axioms of probability theory. In this case, these values were obtained from domain experts' opinions.

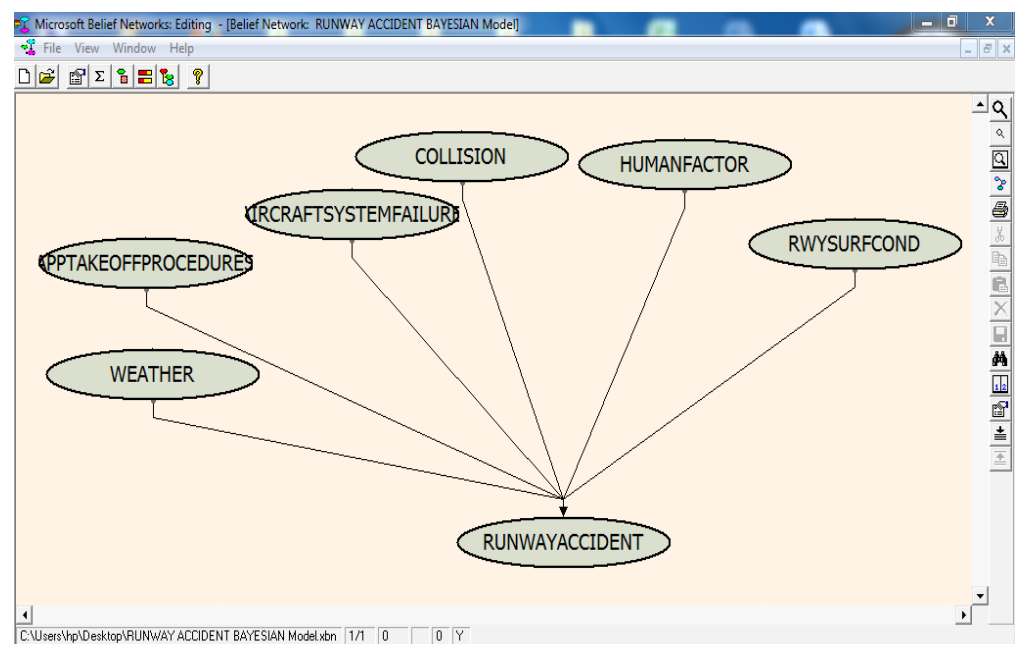

Fig. 1.

Influence Diagram for Relationship between Runway Hazards and Consequence Magnitude

\section{Estimation of Prior Probability and Conditional Probability of Node Variables}

After the establishment of BN influence diagram for the occurrence of consequence/ magnitude of runway accident, historical data and domain experts were used to estimate the values of prior and conditional probabilities. While historical data were used to estimate the prior probabilities of the parent nodes; domain experts were used to populate the conditional probabilities. 
Historical data of Nigeria aviation sector for twelve years (2000-2011) was obtained from the Accident Investigation Bureau (AIB). Fifty nine (59) runway accidents occurred during this period and these accidents were categorised according to their causal factors (Table 1). It should be noted that the prior probability was estimated using frequency of occurrence of the accident. For instance, runway accident due to runway surface conditions (RSC) occurs nine times given an estimated probability of $0.15(15 \%)$. The values of other categories are provided in Table 1. From this illustration, Table 2 shows the prior probabilities of root nodes.

Furthermore, the domain experts were asked to estimate the minimum and maximum likelihood in every conditional influence involving two or more variables of the network. The elicitation process was carried out using recursive technique (Delphi method). The following assumptions were made:

1. The values of conditional probabilities were given by estimation.

2. The child node variable, runway accident has three states: minor, serious and fatal. The parent nodes have two states respectively (Fig. 1).

3. The values of the conditional probabilities were given by using fuzzy membership to describe the probabilities. In this case, triangular fuzzy number $(l, m$ and $u$ ) was used to represent the lower least likely value, the most likely value and the upper least likely value.

Table 3 gives the conditional probabilities of the child node (runway accident) given the occurrence of states of the parent nodes; runway surface condition (RSC), human factors (HF), weather (WE), collision (CL), aircraft system failure (ASF) and approach/ take-off procedures (ATP). The triangular fuzzy number of each state was defuzzificated to obtain the crisp value as shown in Table 3. In Table 3, the crisp value is provided for each possible combination of states of parent nodes $(2 \times 2 \times 2 \times 2 \times 2 \times 2 \times 3=192$ in this case).

The defuzzification method of triangular center of gravity was used to calculate the crisp value given as (Li et al., 2012):

$F_{i}=\frac{\left(u_{i}-l_{i}\right)+\left(m_{i}-l_{i}\right)}{3}+l_{i}$

Where, $F_{i}(i=1,2, \ldots n)$ is a crisp value transformed from fuzzy membership function. It is necessary to transform the fuzzy value to crisp values in order to conduct Bayesian inference. Fuzzy prior probabilities were transformed into crisp values using Eq. (1).

Table 1

Frequency of Occurrence of Runway Accidents Caused by Runway Accident Hazards

\begin{tabular}{|c|c|c|c|c|c|c|c|c|c|c|c|c|c|c|}
\hline $\begin{array}{l}\text { Runway } \\
\text { Accident } \\
\text { Hazards }\end{array}$ & 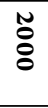 & ํㅗㅇ & ָ̊ & ¿ & ํㅜㅇ & ָ̊ & ํ. & స్ & $\stackrel{N}{\circ}$ & ำ & 룽 & 象 & $\begin{array}{l}\text { Sub- } \\
\text { Total }\end{array}$ & Prior Probability \\
\hline RSC & - & 2 & - & - & 1 & 4 & 1 & - & - & - & 1 & - & 9 & 0.15 \\
\hline WE & - & 1 & - & 1 & - & 1 & 1 & - & - & - & 1 & - & 5 & 0.08 \\
\hline $\mathrm{CL}$ & - & - & - & - & 1 & 1 & - & 1 & 2 & 1 & 1 & 1 & 8 & 0.14 \\
\hline ASF & 1 & - & - & 2 & 1 & 4 & 3 & - & - & 1 & 1 & - & 13 & 0.22 \\
\hline ATP & - & 3 & 2 & 1 & - & - & - & - & - & 1 & 3 & 1 & 11 & 0.19 \\
\hline $\mathrm{HF}$ & 1 & - & - & 3 & 2 & 2 & 3 & - & - & - & 1 & 1 & 13 & 0.22 \\
\hline
\end{tabular}




\section{Bayesian Network Causal Inference}

Causal inference is a probability process of drawing an inference from causes, and it is top-down. The calculation of the probability of the occurrence of consequence magnitude is determined using Bayesian inference mechanism given the causes and evidences. The scenario that generates the consequence magnitude of runway accident is the occurrence of the runway hazards. The probability of runway accident consequence magnitude can be decomposed into two broad components:

1. the probability of occurrence of states of runway hazards; and

2. the probability of occurrence of consequence magnitude of runway accident given the occurrence of each combination of states of runway hazards.

Table 2

Prior Probabilities of Root/Parent Nodes

\begin{tabular}{llll}
\hline S/N & Variables & States & Prior Probabilities \\
\hline \multirow{2}{*}{1} & \multirow{2}{*}{ Runway Surface Condition (RSC) } & Good & 0.85 \\
& & Bad & 0.15 \\
& \multirow{2}{*}{ Weather (WE) } & Good & 0.92 \\
3 & \multirow{2}{*}{ Collision (CL) } & Bad & 0.08 \\
& & No & 0.86 \\
4 & \multirow{2}{*}{ Aircraft System Failure (ASF) } & Yes & 0.14 \\
& & No Failure & 0.78 \\
5 & \multirow{2}{*}{ Approach/Take off Procedures (ATP) } & Failure & 0.22 \\
& & Followed & 0.81 \\
6 & Human Factors (HF) & Faulted & 0.19 \\
& & Human Reliability & 0.78 \\
\end{tabular}

Table 3

Conditional Probabilities of the Child Node (Runway Accident) Given the States of the Parent Nodes

\begin{tabular}{|c|c|c|c|c|c|c|c|c|c|}
\hline \multicolumn{7}{|c|}{ Runway Accident Hazard States } & \multicolumn{3}{|c|}{ Conditional Probability for Runway Accident states } \\
\hline $\mathbf{S} / \mathbf{N}$ & RSC & WE & $\mathbf{C L}$ & ASF & ATP & HE & Minor & Serious & Fatal \\
\hline 1 & Good & Good & Yes & No Failure & Followed & HR & 0.80 & 0.15 & 0.05 \\
\hline 2 & Good & Good & Yes & No Failure & Followed & $\mathrm{HE}$ & 0.60 & 0.30 & 0.10 \\
\hline 3 & Good & Good & Yes & No Failure & Faultered & HR & 0.60 & 0.25 & 0.15 \\
\hline 4 & Good & Good & Yes & No Failure & Faultered & $\mathrm{HE}$ & 0.40 & 0.30 & 0.30 \\
\hline 5 & Good & Good & Yes & Failure & Followed & HR & 0.50 & 0.25 & 0.25 \\
\hline 6 & Good & Good & Yes & Failure & Followed & $\mathrm{HE}$ & 0.25 & 0.35 & 0.40 \\
\hline 7 & Good & Good & Yes & Failure & Faultered & HR & 0.50 & 0.25 & 0.25 \\
\hline 8 & Good & Good & Yes & Failure & Faultered & $\mathrm{HE}$ & 0.20 & 0.30 & 0.50 \\
\hline 9 & Good & Good & No & No Failure & Followed & HR & 0.90 & 0.075 & 0.025 \\
\hline 10 & Good & Good & No & No Failure & Followed & $\mathrm{HE}$ & 0.80 & 0.15 & 0.05 \\
\hline 11 & Good & Good & No & No Failure & Faultered & HR & 0.70 & 0.20 & 0.10 \\
\hline 12 & Good & Good & No & No Failure & Faultered & $\mathrm{HE}$ & 0.65 & 0.20 & 0.15 \\
\hline 13 & Good & Good & No & Failure & Followed & HR & 0.65 & 0.20 & 0.15 \\
\hline 14 & Good & Good & No & Failure & Followed & $\mathrm{HE}$ & 0.50 & 0.30 & 0.20 \\
\hline 15 & Good & Good & No & Failure & Faultered & HR & 0.65 & 0.20 & 0.15 \\
\hline 16 & Good & Good & No & Failure & Faultered & $\mathrm{HE}$ & 0.40 & 0.30 & 0.30 \\
\hline 17 & Good & $\mathrm{Bad}$ & Yes & No Failure & Followed & HR & 0.80 & 0.15 & 0.05 \\
\hline 18 & Good & $\mathrm{Bad}$ & Yes & No Failure & Followed & $\mathrm{HE}$ & 0.70 & 0.20 & 0.10 \\
\hline 19 & Good & $\mathrm{Bad}$ & Yes & No Failure & Faultered & HR & 0.70 & 0.20 & 0.10 \\
\hline 20 & Good & $\mathrm{Bad}$ & Yes & No Failure & Faultered & $\mathrm{HE}$ & 0.60 & 0.25 & 0.15 \\
\hline
\end{tabular}




\begin{tabular}{|c|c|c|c|c|c|c|c|c|c|}
\hline 21 & Good & $\mathrm{Bad}$ & Yes & Failure & Followed & $\mathrm{HR}$ & 0.70 & 0.20 & 0.10 \\
\hline 22 & Good & Bad & Yes & Failure & Followed & $\mathrm{HE}$ & 0.40 & 0.30 & 0.30 \\
\hline 23 & Good & $\mathrm{Bad}$ & Yes & Failure & Faultered & HR & 0.40 & 0.30 & 0.30 \\
\hline 24 & Good & $\mathrm{Bad}$ & Yes & Failure & Faultered & $\mathrm{HE}$ & 0.30 & 0.30 & 0.40 \\
\hline 25 & Good & $\mathrm{Bad}$ & No & No Failure & Followed & $\mathrm{HR}$ & 0.80 & 0.15 & 0.05 \\
\hline 26 & Good & $\mathrm{Bad}$ & No & No Failure & Followed & $\mathrm{HE}$ & 0.70 & 0.20 & 0.10 \\
\hline 27 & Good & $\mathrm{Bad}$ & No & No Failure & Faultered & $\mathrm{HR}$ & 0.80 & 0.15 & 0.05 \\
\hline 28 & Good & Bad & No & No Failure & Faultered & $\mathrm{HE}$ & 0.60 & 0.20 & 0.20 \\
\hline 29 & Good & $\mathrm{Bad}$ & No & Failure & Followed & $\mathrm{HR}$ & 0.70 & 0.20 & 0.10 \\
\hline 30 & Good & Bad & No & Failure & Followed & $\mathrm{HE}$ & 0.60 & 0.25 & 0.15 \\
\hline 31 & Good & $\mathrm{Bad}$ & No & Failure & Faultered & HR & 0.40 & 0.30 & 0.30 \\
\hline 32 & Good & $\mathrm{Bad}$ & No & Failure & Faultered & $\mathrm{HE}$ & 0.20 & 0.30 & 0.50 \\
\hline 33 & Bad & Good & Yes & No Failure & Followed & $\mathrm{HR}$ & 0.75 & 0.15 & 0.10 \\
\hline 34 & Bad & Good & Yes & No Failure & Followed & $\mathrm{HE}$ & 0.70 & 0.20 & 0.10 \\
\hline 35 & Bad & Good & Yes & No Failure & Faultered & $\mathrm{HR}$ & 0.60 & 0.20 & 0.20 \\
\hline 36 & $\mathrm{Bad}$ & Good & Yes & No Failure & Faultered & $\mathrm{HE}$ & 0.50 & 0.25 & 0.25 \\
\hline 37 & Bad & Good & Yes & Failure & Followed & $\mathrm{HR}$ & 0.60 & 0.30 & 0.10 \\
\hline 38 & Bad & Good & Yes & Failure & Followed & $\mathrm{HE}$ & 0.30 & 0.30 & 0.40 \\
\hline 39 & $\mathrm{Bad}$ & Good & Yes & Failure & Faultered & $\mathrm{HR}$ & 0.40 & 0.3 & 0.30 \\
\hline 40 & Bad & Good & Yes & Failure & Faultered & $\mathrm{HE}$ & 0.20 & 0.30 & 0.50 \\
\hline 41 & Bad & Good & No & No Failure & Faultered & HR & 0.60 & 0.20 & 0.20 \\
\hline 42 & $\mathrm{Bad}$ & Good & No & No Failure & Followed & $\mathrm{HE}$ & 0.60 & 0.20 & 0.20 \\
\hline 43 & Bad & Good & No & No Failure & Faultered & $\mathrm{HR}$ & 0.70 & 0.20 & 0.10 \\
\hline 44 & $\mathrm{Bad}$ & Good & No & No Failure & Faultered & $\mathrm{HE}$ & 0.50 & 0.20 & 0.30 \\
\hline 45 & Bad & Good & No & Failure & Followed & HR & 0.60 & 0.25 & 0.15 \\
\hline 46 & Bad & Good & No & Failure & Followed & $\mathrm{HE}$ & 0.20 & 0.35 & 0.45 \\
\hline 47 & Bad & Good & No & Failure & Faultered & HR & 0.70 & 0.20 & 0.10 \\
\hline 48 & Bad & Good & No & Failure & Faultered & $\mathrm{HE}$ & 0.15 & 0.35 & 0.50 \\
\hline 49 & Bad & Bad & Yes & No Failure & Followed & $\mathrm{HR}$ & 0.70 & 0.25 & 0.05 \\
\hline 50 & Bad & $\mathrm{Bad}$ & Yes & No Failure & Followed & $\mathrm{HE}$ & 0.60 & 0.10 & 0.30 \\
\hline 51 & $\mathrm{Bad}$ & $\mathrm{Bad}$ & Yes & No Failure & Faultered & HR & 0.70 & 0.20 & 0.10 \\
\hline 52 & $\mathrm{Bad}$ & $\mathrm{Bad}$ & Yes & No Failure & Faultered & $\mathrm{HE}$ & 0.10 & 0.60 & 0.3 \\
\hline 53 & Bad & $\mathrm{Bad}$ & Yes & Failure & Followed & $\mathrm{HR}$ & 0.15 & 0.60 & 0.25 \\
\hline 54 & Bad & Bad & Yes & Failure & Followed & $\mathrm{HE}$ & 0.10 & 0.30 & 0.60 \\
\hline 55 & $\mathrm{Bad}$ & $\mathrm{Bad}$ & Yes & Failure & Faultered & $\mathrm{HR}$ & 0.10 & 0.30 & 0.60 \\
\hline 56 & Bad & $\mathrm{Bad}$ & Yes & Failure & Faultered & $\mathrm{HE}$ & 0.05 & 0.15 & 0.80 \\
\hline 57 & $\mathrm{Bad}$ & $\mathrm{Bad}$ & No & No Failure & Followed & $\mathrm{HR}$ & 0.85 & 0.10 & 0.05 \\
\hline 58 & $\mathrm{Bad}$ & $\mathrm{Bad}$ & No & No Failure & Followed & $\mathrm{HE}$ & 0.40 & 0.30 & 0.30 \\
\hline 59 & Bad & $\mathrm{Bad}$ & No & No Failure & Faultered & HR & 0.70 & 0.20 & 0.10 \\
\hline 60 & Bad & Bad & No & No Failure & Faultered & $\mathrm{HE}$ & 0.40 & 0.30 & 0.30 \\
\hline 61 & $\mathrm{Bad}$ & Bad & No & Failure & Followed & $\mathrm{HR}$ & 0.50 & 0.20 & 0.30 \\
\hline 62 & Bad & Bad & No & Failure & Followed & $\mathrm{HE}$ & 0.10 & 0.20 & 0.70 \\
\hline 63 & Bad & $\mathrm{Bad}$ & No & Failure & Faultered & $\mathrm{HR}$ & 0.10 & 0.20 & 0.70 \\
\hline 64 & $\mathrm{Bad}$ & $\mathrm{Bad}$ & No & Failure & Faultered & $\mathrm{HE}$ & 0.05 & 0.15 & 0.80 \\
\hline
\end{tabular}

Therefore, the probability of runway accident fatal/death/aircraft destroyed accidents) is consequence magnitude (minor, serious and given by the expression below:

Prob (Minor runway accident)

$=\operatorname{Prob}($ Runway hazards states $) \times$ Prob (Minorrunway accident $\mid$ Runway hazards states) Prob (Serious runway accident)

$$
\begin{aligned}
& =\text { Prob }(\text { Runway hazards states }) \\
& \times \text { Prob }(\text { Serious /Damage runway accident|Runway hazards states) }
\end{aligned}
$$

Prob (Fatal runway accident)

$=$ Prob (Runway hazards states $) \times$ Prob (Fatal runway accident $\mid$ Runway hazards states)

Mathematically,

$P\left(W_{i}\right)=\sum_{j=1}^{m}\left(P\left(H_{j}\right) \times \prod_{k=1}^{m} P\left(W_{i} \mid p a\left(w_{i, k}\right)\right)\right)$ 
where,

$P\left(W_{i}\right)=$ Probability of occurrence $(\mathrm{RWY}$ = MINOR, SERIOUS and FATAL) of consequence magnitude of runway accidents,

$P\left(H_{j}\right)=$ Joint probability of occurrence of runway hazards states,

$\prod_{k=1}^{m} P\left(W_{i} \mid p a\left(w_{i, k}\right)\right)=$ Conditiona 1 probability of occurrence of consequence magnitude given the occurrence of $k$ combination of states of parents' node of variable $W_{i}$,

$n=$ number of runway hazards and

$m=$ number of states (combinations of states $=64$ ) of parents nodes.

\section{The Improved Air Traffic Accident Model}

Adebiyi (2008) had developed a cost estimation model for air traffic accidents. From this model, the probability of accident occurrence was determined using the expression in Eq. (3).

$\rho=\frac{\text { Number of accident class } i}{\text { Total number of accidents }}$

The expression does not present the true probability of consequence magnitude given the occurrence of cause of accidents. Hence Bayesian Network was used to model this shortcoming (Eq. (2)).

From Adebiyi (2008), the estimated cost of air traffic accidents is given in Eq. (4).

$C_{i}=\rho_{i}\left(f_{i}(Y Z)+N\left(\frac{(1+t)^{L-T}}{(1+t)^{L-T}-1}\right)+Q_{I}+R \theta_{i}\right)$

This model has three classifications that make it up; viz:

Human severity: $f_{i}(Y Z)$

Aircraft damaged/destroyed:

$N\left(\frac{(1+t)^{L-T}}{(1+t)^{L-T}-1}\right)+Q_{I}$

Opportunity cost: $R \theta_{i}$

Furthermore, the economic implication cost of damages and hull losses of aircraft from accident was modelled with the assumption of real interest rate (constant naira, inflation free). Market interest rate which incorporates inflation is now incorporated (to relax the assumption). The market interest rate $t_{f}$ is given in Eq. (5) (Akinyemi et al., 2012).

$t_{f}=i+f+(i \times f)$

Where, $f$ is the inflation rate and $i$ is the economic rate.

Now substituting these expressions, we have the improved model for estimating the cost of runway accident given as:

$C_{i}=\sum_{j=1}^{m}\left(P\left(H_{j}\right) \times \prod_{k=1}^{m} P\left(W_{i} \mid p a\left(w_{i, k}\right)\right)\right)\left(f_{i}(Y Z)+N\left(\frac{\left(1+t_{f}\right)^{L-T}}{\left(1+t_{f}\right)^{L-T}-1}\right)+Q_{I}+R \theta_{i}\right)$

where, $t_{f}=i+f+(i \times f)$. 


\section{Model Application}

The improved model comprises of Bayesian discrete probability distribution with other model parameters linked together by linear and polynomial functions. The Bayesian discrete probability distribution comprises of six parent/root nodes viz: runway surface conditions, weather, collision, aircraft system failures, approach/takeoff procedures and human factors each with two states while the child node (runway accident) has consequence magnitude as its state viz: fatal, serious and minor. Also, the constant naira effect in the model was removed with the addition of the effect of inflation. Microsoft Belief Networks Software was used to solve Eq. (2) where the values of probability of runway accident consequence magnitude were obtained as follows:

Probability of minor runway accident $=$ 0.7603;
Probability of serious runway accident $=$ 0.1547 and

Probability of fatal runway accident $=$ 0.0850 .

Subsequently, substituting the model estimates in Table 4; the cost estimates of runway accident consequences obtained through the improved model are:

Minor runway accident $=\$ 23,813.52$;

Serious runway accident $=\$ 20,052.64$ and Fatal runway accident $=\$ 772,856.06$.

It should be noted that in calculating the runway accident cost estimation, the annuity

term in the model $\left(\frac{\left(1+t_{f}\right)^{L-T}}{\left(1+t_{f}\right)^{L-T}-1}\right)$ equals zero for serious and minor runway accidents since there is no hull losses or aircraft destroyed. But for fatal runway accident where there is hull losses/aircraft destroyed; the term takes its value.

Table 4

Estimates of Model Parameters

\begin{tabular}{lll}
\hline Parameters & Description of Model Parameters & Estimates \\
\hline $\mathrm{Y}$ & Establishment average annual Salary (\$/year) & \$34, 848.48 \\
$\mathrm{Z}$ & Establishment maximum allowable service year & 35 YEARS \\
$\mathrm{L}$ & Service life of the aircraft involve in the accident & 31 YEARS \\
$\mathrm{T}$ & Usage life of aircraft & 22 YEARS \\
$\mathrm{t}$ & Real interest rate & $20 \%$ \\
$f$ & Inflation rate & $8 \%$ \\
$\mathrm{~N}$ & Acquisition cost of aircraft destroyed & $\$ 300,000,000.00$ \\
$\theta_{1}$ & Period of idleness of aircraft due to fatal runway accident & \\
$\theta_{2}$ & Period of idleness of aircraft due to serious runway accident & 14 DAYS \\
$\theta_{3}$ & Period of idleness of aircraft due to minor runway accident & 3 DAYS \\
$\mathrm{R}$ & Flight rate & $\$ 340$ \\
$\mathrm{f}_{1}$ & Degree of severity due to fatal runway accident & 1 \\
$\mathrm{f}_{2}$ & Degree of severity due to serious runway accident & 0.003 \\
$\mathrm{f}_{3}$ & Degree of severity due to minor runway accident & 0 \\
$\mathrm{Q}_{1}$ & Material loss due to fatal runway accident & $\$ 272,727.27$ \\
$\mathrm{Q}_{2}$ & Material loss due to serious runway accident & $\$ 121,212.12$ \\
$\mathrm{Q}_{3}$ & Material loss due to minor runway accident & $\$ 30,303.03$ \\
$P\left(W_{1}\right)$ & Probability of occurrence of fatal runway accident & 0.0850 \\
$P\left(W_{2}\right)$ & Probability of occurrence of serious runway accident & 0.1547 \\
$P\left(W_{3}\right)$ & Probability of occurrence of minor runway accident & 0.7603 \\
\hline
\end{tabular}


The critical analysis of the estimates revealed that aircraft damaged/destroyed accounted for $96 \%$ of the cost in fatal runway accidents. This is due to the high acquisition cost of new aircraft. The material loss is prominent in both serious and minor runway accidents accounting for $93.5 \%$ and $96.8 \%$ of the costs, respectively. The human severity factor has a contribution of $3 \%$ in both serious and fatal runway accidents. These are indications of the difficulty in placing value on human life, thereby supporting the statement that estimating the cost of accidents depends greatly on location and circumstances (Harold and Moriarity, 1990; Kirkland et al., 2004). Although fatal runway accidents have the greatest economic implication, minor runway accidents have the highest frequency of occurrence. A total of 59 runway accidents were recorded in the 12 years period of 2000 to 2011 corresponding to an incidence of 5 runway accidents per year. For instance, if there is no runway safety programme in place and an estimate of five (5) runway accidents occurs per year, there will be a monetary loss (injuries, loss of lives/material and property damaged/destroyed) in the estimated range of $\$ 100,000-\$ 38.8$ million annually. The information from the model application will be useful for advising management on the magnitude and the cost of consequences of runway accidents and the need and benefits of runway safety strategies.

\section{Bayesian Network Diagnostic Inference}

Diagnostic inference is a probabilistic inference process of drawing a cause from conclusion, and is bottom-up inference. Its objective is obtaining the probability of occurrence of causal factors causing a particular consequence. Assuming that fatal runway accident occurs and it is requested to inference the degree to which this unexpected consequence magnitude was related to the runway accident hazards i.e. the parent nodes. Therefore, the posterior probability for bad runway surface conditions is given as:

$P(R S C=$ Bad $\mid R W Y=$ Fatal $)=\frac{P(R S C=B a d) \times P(R S C=B A D \mid R W Y=F a t a l)}{P(R W Y=\text { Fatal })}$

Using the Microsoft Bayesian Belief Network software which evaluates Bayesian probability models, the value for this expression is given as:

$$
P(R S C=B a d \mid R W Y=\text { Fatal })=0.1661
$$

Similarly, the posterior probability of other parent nodes given observed fatal runway accident is computed respectively as:

$$
\begin{gathered}
P(W E=\text { Bad } \mid R W Y=\text { Fatal })=0.1242 \\
P(C L=\text { Yes } \mid R W Y=\text { Fatal })=0.2062 \\
P(\text { ASF }=\text { Failure } \mid R W Y=\text { Fatal })=0.4758 \\
P(\text { ATP }=\text { Faultered } \mid R W Y=\text { Fatal })=0.3184 \\
P(\text { HF }=\text { HE } \mid R W Y=\text { Fatal })=0.3429
\end{gathered}
$$

Comparing posterior probability with prior probability (Table 2 ), it can be noted that there are some changes in the probability of occurrence of parent nodes when fatal runway accident is observed. The percentage change is shown in Table 5.

In Table 5, it is shown that there are significant changes in the probability of occurrence of ASF $=$ Failure, ATP $=$ Faultered, HF = $\mathrm{HE}, \mathrm{WE}=\mathrm{Bad}$ and $\mathrm{CL}=$ Yes (increased by $116.273 \%, 67.579 \%, 55.864 \%, 55.25 \%$ and $47.286 \%$, respectively) when fatal runway accident was observed. This implies that the runway accident is sensitive to nodes aircraft system failure, approach/takeoff procedures, human factors, weather and collision, and the most influential causal factor is aircraft system failure i.e. once fatal runway accident occurs, it is more likely that aircraft system failure, approach/takeoff procedures, human factors, 
weather and collision are the main causal factors. The influential contribution of aircraft system failure to air traffic accident in Nigeria Aviation Sector is obvious because most of the aircraft flying the Nigerian airspace has passed there service year. The contributory effect of runway surface condition is the least with a change rate of $10.733 \%$.

From the above critical analysis, it is obvious that the state of aircraft, appropriate and understandable approach/takeoff procedures from regulatory body (both local and international) and adequate training for human component of the system should be given needed attention.

The information from the above evaluation will be useful for advising management on the magnitude and the cost of consequences for runway accidents of different types and the benefits of preventive strategies.

\section{Table 5}

The Change Rate Comparing Prior Probability with Posterior Probability

\begin{tabular}{|c|c|c|c|c|c|c|}
\hline $\begin{array}{l}\text { Variable } \\
\text { State }\end{array}$ & $\mathrm{RSC}=\mathrm{Bad}$ & $\mathrm{WE}=\mathrm{Bad}$ & $\mathrm{CL}=\mathrm{Yes}$ & ASF=Failure & $\mathrm{ATP}=$ Faultered & Human Factor=Human Error \\
\hline $\begin{array}{l}\text { Prior } \\
\text { Probability }\end{array}$ & 0.15 & 0.08 & 0.14 & 0.22 & 0.19 & 0.22 \\
\hline $\begin{array}{l}\text { Posterior } \\
\text { probability }\end{array}$ & 0.1661 & 0.1242 & 0.2062 & 0.4758 & 0.3184 & 0.3429 \\
\hline $\begin{array}{l}\text { Change } \\
\text { rate } \%\end{array}$ & 10.733 & 55.25 & 47.286 & 116.273 & 67.579 & 55.864 \\
\hline
\end{tabular}

\section{Conclusion}

In this study, a cost estimation model was improved using Bayesian Network discrete probability distribution and market interest rate (with inflation rate). This improved model was applied to the data collected from the Federal Aviation Authority, Nigeria. The improved model estimated the costs of fatal, serious, and minor runway accidents as $\$ 772,856.06, \$ 20,052.64$ and $\$ 23,813.52$ respectively. In addition, the Bayesian network diagnostic inference reveals that aircraft system failure, approach/takeoff procedures, human factors and weather conditions are sensitive to the occurrence of runway accident. Based on this, it could be concluded that fatal accidents have the greatest contribution to adversity, while minor runway accidents have the greatest probability of occurrence in the Nigeria aviation industry.

\section{References}

Adebiyi, K.A. 2008. Estimation of Air Traffic Accident Cost in Nigeria, Pacific Journal of Science and Technology, 9(2): 420-425.

Akinyemi, O.O.; Adebiyi, K.A. 2015. Assessment of runway accident hazards in Nigeria aviation sector, International Journal of Transport and Traffic Engineering, 5(2): 82-92.

Akinyemi, O.O.; Nwaokocha, C.N.; Adesanya, A.O. 2012. Evaluation of Corrosion Cost of Crude Oil Processing Industry, Journal of Engineering, Science and Technology, 7(4): 438-451. 
Aviation Safety Network. 2008. Incident and Accident. Flight Safety Foundation. Available from Internet: $<$ www.flightsafety.org >.

Christoph, V.; Carole, U.; Uwe, K. 2008. Simulator evaluation of novel surface movement awareness and alerting system (SMAAS) for runway incursion avoidance. In Proceedings of the 26th Congress of International Council of the Aeronautical Sciences (ICAS), Anchorage, Alaska.

Federal Aviation Administration (FAA). 2008a. Analysis of Aircraft Overruns and Undershoots for Runway Safety Areas. Airport Cooperative Research Programme (ACRP) Report 3.

Federal Aviation Administration (FAA). 2008b. Runway Safety Report: Trends and Initiatives at US Towered Airports, FY2004 through FY2007. Federal Aviation Administration.

Federal Aviation Administration (FAA). 2012. Runway Safety Report: Trends and Initiatives at US Towered Airports, FY2004 through FY2007. Federal Aviation Administration.

Harold, E.R.; Moriarty, B. 1990. System Safety Engineering and Management. A Wiley Science Publication. John Wiley and Sons INC. New York.USA.

James, R.E.; Bradley, R.H.; Maria, P.K.; Harald, W.; Bernays, D.J. 2006. Operational evaluation of runway status lights, Lincoln Laboratory Journal, 16(1): 123-146.

Jones, B.; Jenkinson, I.; Yang, Z.; Wang, J. 2010. The use of Bayesian network modelling for modelling of maintenance planning in a manufacturing industry, Reliability Engineering and System Safety, 95(3): 267-277.

Kirkland, I.D.L.; Caves, R.E.; Humphreys, I.M.; Pitfield, D.E. 2004. An Improved methodology for assessing risk in aircraft operations at airports applied to runway overruns, Safety Science, 42(10): 891-905.
Li, P-C.; Chen, G-H.; Dai, L-C.; Zhang, L. 2012. A fuzzy Bayesian network approach to improve the quantification of organizational influences in HRA frameworks, Safety Science, 50(7): 1569-1583.

Luxhøj, J.T.; Jalil, M.; Jones, S.M. 2006. A risk based decision support tool for evaluating aviation technology integration in the national airspace system. In Proceedings of the AIAA'S 3rd Annual Aviation Technology, Integration and Operation (ATIO) Technical Forum. Denver. Colorado.

Luxhøj,J.T. 2003. Probabilistic causal Analysis for System Safety Risk Assessments in commercial Transport. In Proceedings of the second workshop on the investigation and reporting of incidents and Accident (IRIA). 17-38.

Rankin, W.B. 2006. Runway Incursions: A critical examination of Airport driver training methods. $\mathrm{PhD}$ thesis submitted to the Department of Business and Technology Management, North Central University, Prescott, Arizona.

Rasmussen, N.C. 1981. The application of probabilistic risk assessment techniques to energy technologies, Annual Review of Energy, 6: 123-138.

Scarborough, A.; Pounds, J.; Bailey, L. 2003. Human factors classification of runway incursion associated with V/PD. FAA Civil Aeromedical Institute, Oklahoma City.

Scarborough, A.; Pounds, J.; Bailey, L. 2008. Analysing Vehicle operator deviations. FAA Civil Aeromedical Institute, Oklahoma City.

Stroeve, S.; Blom, H.; Bakker, B. 2006. Safety risk impact analysis of an ATC runway incursion alert system. National Aerospace laboratory. EUROCONTROL safety R\&D seminar, Barcelona, Spain.

Ting, K.P. 2007. The effectiveness of surface movement radar in the prevention of runway incursions: A case study. M.Sc. thesis submitted to the Department of Air Transport, Cranfield University. 
Werfelman, L. 2008. Safety on the straight and narrow flight. Flight Safety Foundation. Available from Internet: $<w w w . f l i g h t s a f e t y . o r g>$.

Williams, P. 2008. Runway Incursions: A review based on Transport Accident investigation commission report 07-005. Australia and New Zealand Societies of Air Safety Investigators Annual Seminar.

Wischmeyer, E. 2007. 1001 Runway Incursions. Available from Internet: <www.greatusermanuals.com>.

Yong, K.; Wang, T. 2001. Human Factors analysis and methodology of the SQ006 accident. In Proceedings of Aviation Safety Council of Taiwan, Taiwan. 